\title{
Characteristics of primary care practices associated with high quality of care
}

\begin{abstract}
Marie-Dominique Beaulieu MD MSc, Jeannie Haggerty PhD, Pierre Tousignant MD MSc, Janet Barnsley PhD, William Hogg MD MSc, Robert Geneau PhD, Éveline Hudon MD MSc, Réjean Duplain MD, Jean-Louis Denis PhD, Lucie Bonin MD MSc, Claudio Del Grande MSc, Natalyia Dragieva MSc
\end{abstract}

Competing interests: Marie-Dominique Beaulieu is President of the College of Family Physicians of Canada (CFPC). She did not hold this position when the study was conducted and the article written. The CFPC had no involvement in the conduct of this research. The opinions expressed are those of the authors and do not represent those of the CFPC. Jean-

Louis Denis has served as a consultant for the Canadian Foundation for Healthcare Improvement. No competing interests declared by any other author.

This article has been peer reviewed.

Correspondence to: Marie-Dominique Beaulieu, marie-dominique.beaulieu @ umontreal.ca

CMAJ 2013. DOI:10.1503 /cmaj.121802

\section{- Abstract}

Background: No primary practice care model has been shown to be superior in achieving highquality primary care. We aimed to identify the organizational characteristics of primary care practices that provide high-quality primary care.

Methods: We performed a cross-sectional observational study involving a stratified random sample of 37 primary care practices from 3 regions of Quebec. We recruited 1457 patients who had 1 of 2 chronic care conditions or 1 of 6 episodic care conditions. The main outcome was the overall technical quality score. We measured organizational characteristics by use of a validated questionnaire and the Team Climate Inventory. Statistical analyses were based on multilevel regression modelling.

Results: The following characteristics were strongly associated with overall technical

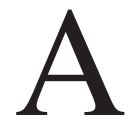
health care system is only as strong as its primary care sector, ${ }^{1}$ which provides "entry into the system for all new needs and problems, provides person-focused (not disease-oriented) care over time, provides care for all but very uncommon or unusual conditions ..."” Patient enrolment, team-based care, information technology, and funding and remuneration schemes that foster comprehensiveness and collaboration are key characteristics of effective primary care systems. ${ }^{3}$ None can be singled out as the most determining, but how they are clustered defines a limited set of organizational models that have been associated with a variety of outcomes. ${ }^{4}$ Canadian provinces have implemented different primary care models with different scopes of changes. ${ }^{5}$ Research has not yet identified a "winning" model. For example, in Ontario, community health centres deliver better chronic illness care ${ }^{6}$ but have less accessibility than feefor-service enrolment models, ${ }^{7}$ and no model provided more comprehensive preventive care. ${ }^{8}$ Walk-in clinics achieved better quality scores quality of care score: physician remuneration method $(27.0 ; 95 \%$ confidence interval $[\mathrm{Cl}]$ 19.0-35.0), extent of sharing of administrative resources $(7.6 ; 95 \% \mathrm{Cl} 0.8-14.4)$, presence of allied health professionals $(15.3 ; 95 \%$ Cl 5.425.2) and/or specialist physicians (19.6; $95 \% \mathrm{Cl}$ 8.3-30.9), the presence of mechanisms for maintaining or evaluating competence (7.7; $95 \% \mathrm{Cl} 3.0-12.4)$ and average organizational access to the practice $(4.9 ; 95 \% \mathrm{Cl} 2.6-7.2)$. The number of physicians $(1.2 ; 95 \% \mathrm{Cl} 0.6-1.8)$ and the average Team Climate Inventory score (1.3; $95 \% \mathrm{Cl} 0.1-2.5)$ were modestly associated with high-quality care.

Interpretation: We identified a common set of organizational characteristics associated with high-quality primary care. Many of these characteristics are amenable to change through practice-level organizational changes.

than did family medicine clinics for treatment of a set of acute problems. ${ }^{9}$ How the work is organized may be as important, if not more important, than what the model is called.

These observations suggest that the challenges associated with providing high-quality services differ depending on the nature of care considered. ${ }^{9-11}$ Even if chronic illness is a major challenge, the quality of care must not be improved at the expense of accessibility, preventive or good episodic care, which are all essential components of primary care.

In this study, we report the results of the quantitative component of a multimethod observational study conducted in Quebec to determine which organizational characteristics of primary care practices are associated with high-quality care. We sought to find a quality measure of care that would encompass the comprehensive nature of primary care (episodic, chronic and preventive care), and we explored how the contribution of organizational characteristics varied based on the type of care provided. 


\section{Methods}

The 3 primary care organizational models in Quebec are centres locaux de services communautaires (CLSCs) or community health centres, traditional fee-for-service practices, and family medicine groups. Community health centres provide primary care services to a geographically defined population, and the physicians are salaried. Family medicine groups are composed of 8 or more full-time equivalent family physicians (not necessarily all practising at 1 location). Family medicine groups receive funding for 2 registered nurses, an administrative assistant and a secretary, above any existing staff. Patients are enrolled, and physicians may be remunerated by fee-for-service or be salaried. ${ }^{5,12}$

\section{Selection of practices and patients}

This study involved 1 metropolitan region (region 1) and 2 regions with urban, suburban and rural communities (regions 2 and 3). We included practices with at least 3 general practitioners and that had been functioning under the current organizational model for at least 2 years. We excluded university-affiliated teaching practices because they have a distinct funding and staffing model. We used a stratified random sample to ensure representation from each of the 3 models. We aimed for a $50 \%$ response rate.

We included patients who met the following criteria: able to speak English or French; were aged 18 years or older; could self-declare as having 1 or more of the target conditions; and had been known to the practice for at least 2 years (some of the included indicators required a 2-year observation period). Patients were recruited in waiting rooms by trained research technicians. Data were collected between April 2008 and September 2010.

\section{Definition of variables and data collection procedures}

\section{Explanatory variables: organizational characteristics}

The physician in charge of each included practice completed a questionnaire on organizational characteristics related to vision, organizational structure, resources and organizational practices; the Organizational Questionnaire has been validated in French and English (available at www.biomedcentral .com/1471-2296/11/95, additional file \#3). ${ }^{13}$

In addition to these organizational characteristics, we wanted to have a measure of the effectiveness of team process. Team process was measured by use of the Team Climate Inventory, ${ }^{14}$ which was completed by all professionals and staff $(n=471)$ in each practice. We chose this instrument because it is associated with quality of care ${ }^{15-17}$ and has been validated in many languages. ${ }^{18-22} \mathrm{We}$ used the short version provided by the authors of the Team Climate Inventory (Professor Michael West, Lancaster University Management School, UK: personal communication, 2009). ${ }^{14}$ The Team Climate Inventory comprises 4 scales: participation safety (6 items; Cronbach $\alpha$ 0.84) and support for innovation (5 items; Cronbach $\alpha$ 0.81) are scored on a 5-point Likert scale, and vision (4 items; Cronbach $\alpha 0.86$ ) and task orientation (4 items, Cronbach $\alpha$ 0.84 ) are each scored on a 7-point scale.

\section{Patient-related variables}

We collected patient data via use of a questionnaire. The included sociodemographic variables were age, sex and economic status. We used the 12-Item Short Form Survey (SF-12) as a measure of functional capacity. ${ }^{23}$ We computed Ambulatory Care Groups ${ }^{24}$ for each patient from the Régie de l'assurance maladie du Québec (RAMQ) databases to measure morbidity as a control variable.

We measured patients' experiences of care using 3 scales of the Primary Care Assessment Survey ${ }^{25}$ and 1 scale of the Primary Care Assessment Tool $^{26}$ (first contact access, validated in French and English; measures of access during opening hours, evenings and weekends [4 items, Cronbach $\alpha 0.68]$ ). ${ }^{27}$ The Primary Care Assessment Survey's organizational access measures accommodation (6 items, Cronbach $\alpha 0.83$ ), ${ }^{27}$ contextual knowledge of patient (5 items, Cronbach $\alpha 0.90)^{28}$ and interpersonal communication (6 items, Cronbach $\alpha 0.95$ ). ${ }^{29}$

Primary and secondary outcome variables We assessed quality of care for specified conditions: diabetes and coronary artery disease (chronic illness care); upper respiratory tract infection, acute bronchitis, pharyngitis, gastroenteritis, cystitis and acute lower back pain (episodic care); and the interventions recommended for adults by the Canadian Task Force on Preventive Health Services (preventive care; Appendix 1, available at www.cmaj.ca/lookup/suppl/doi :10.1503/cmaj.121802/-/DC1). We selected these conditions based on prevalence and availability of validated evidence-based indicators already used in the United Kingdom ${ }^{30,31}$ and Canada. ${ }^{6,1011,1,32,33}$ For episodic care, the criteria included the performance of appropriate actions and the avoidance of inappropriate ones (e.g., antibiotic prescription or diagnostic imaging). We updated the indicators based on recent guidelines; 2 panels of 6 family physicians confirmed their acceptability and relevance for the Quebec context. The indicators are described in Appendix 1.

The primary outcome measure (overall techni- 
cal quality score) was computed as the average of individual disease-specific composite scores for each patient. We calculated these scores as the sum of all eligible items performed, divided by the number of eligible items for each tracer condition, multiplied by 100 . To characterize chronic illness and episodic care (secondary outcome measures), we computed a technical quality score for chronic care and prevention; these were grouped together because chronic illness care must be comprehensive and include preventive care. We also calculated a technical quality score for episodic care.

We also considered as secondary outcomes the attainment of treatment targets related to the chronic conditions (blood pressure $\leq 140 / 90$ $\mathrm{mm} \mathrm{Hg}$ or 130/80 $\mathrm{mm} \mathrm{Hg}$ for patients with diabetes, low-density lipoprotein cholesterol $\leq 2.1$ $\mathrm{mmol} / \mathrm{L}$, and glycosylated hemoglobin [HbAlc] $\leq 0.07$ ). Trained chart abstractors extracted data from patients' charts. Interobserver reliability was verified throughout the project for over $10 \%$ of charts. The intraclass correlation coefficients were 0.77 for the overall technical quality score, 0.67 for the chronic and preventive care technical quality score, and 0.83 for the episodic care technical quality score.

\section{Sample size calculation}

This study was designed to draw inferences about the practices' organizational characteristics, not their organizational models. We used data available on the means and standard deviations of the aggregated episodic care, ${ }^{9}$ chronic care ${ }^{6,30}$ and preventive care ${ }^{33}$ indicators to estimate the number of practices needed. The estimated sample size was 40 practices to ensure $90 \%$ power to detect a 10 point difference (out of 100) for the primary outcome measure and $80 \%$ power to detect differences of that magnitude for the secondary outcome measures. Improvements of the magnitude of 5\% for some of our indicators (e.g., percentage of patients with controlled high blood pressure, use of acetylsalicylic acid or $\beta$-blockers among patients with coronary diseases) are cost-effective. ${ }^{34}$

Based on previous work establishing the number of cases needed to obtain a valid estimate of quality at the practice level (at least 7 cases for diabetes and coronary diseases ${ }^{30}$ and 15 cases for the episodic care score ${ }^{9}$ ), we aimed to recruit 30 patients with chronic conditions and 20 with episodic problems from each included practice.

\section{Statistical analysis}

We used multilevel regression modelling ${ }^{35}$ to account for the nested nature of the observations (i.e., patients nested in primary care practices). We used multilevel linear regression models to study the effect of organizational characteristics (level 2 variables) on the technical quality scores (level 1 variable) while controlling for patient characteristics (level 1 variables), and we used multilevel logistic regression models to study the attainment of treatment targets (defined as dichotomous variables). For each regression, we first estimated the organizational-level contribution to the total variance (model 1, empty model); we then entered the organizational variables (model 2), followed by the patient-level variables, using backward stepwise selection. We used SPSS version 17.0.1 (SPSS Inc.) and SAS version 9.2 (SAS Institute Inc.) software.

\section{Ethics approval}

This study was approved by the Research Ethics Committee of the Université de Montréal Hospital Research Centre and by the Commission d'accès à l'information of the province of Quebec.

\section{Results}

Of 107 randomly selected practices, 39 accepted the invitation to participate and 2 did not com-

Table 1: Characteristics of the included practice

\begin{tabular}{|c|c|}
\hline Characteristic & $\begin{array}{c}\text { Included practices, } \\
n / N(\%)\end{array}$ \\
\hline Total sample & $39 * / 107$ (36) \\
\hline \multicolumn{2}{|l|}{ Region } \\
\hline Region 1† & $14 / 45(31)$ \\
\hline Region 2‡ & $15 / 44(34)$ \\
\hline Region 3‡ & $10 / 18(56)$ \\
\hline \multicolumn{2}{|l|}{ Type of practice } \\
\hline Community health centres & $10 / 18(56)$ \\
\hline Traditional fee-for-service & $13 / 64(20)$ \\
\hline Family medicine groups & $16 / 25(64)$ \\
\hline \multicolumn{2}{|l|}{ Remuneration type } \\
\hline Mostly fee-for-service & $27 / 87(31)$ \\
\hline Mostly hourly or salary & $12 / 20(60)$ \\
\hline \multicolumn{2}{|l|}{ Practice size } \\
\hline Small (3 physicians) & $1 / 13 \quad(8)$ \\
\hline Medium (4-9 physicians) & $27 / 65(42)$ \\
\hline Very large ( $\geq 10$ physicians) & $11 / 29(40)$ \\
\hline \multicolumn{2}{|c|}{ Favoured consultation type§ } \\
\hline Mostly with appointment & $17 / 47(36)$ \\
\hline Mostly walk-in & $1 / 13 \quad(8)$ \\
\hline Mixed & $11 / 29(38)$ \\
\hline \multicolumn{2}{|c|}{$\begin{array}{l}\text { *Two practices withdrew during data collection. The final } \\
\text { sample included } 37 \text { practices. } \\
\text { †Metropolitan region. } \\
\text { fUrban/suburban/rural region. } \\
\text { §This information was not available for Region } 3 \text { (total } 89 \\
\text { practices [region } 1 \text { plus region 2]). }\end{array}$} \\
\hline
\end{tabular}


plete the study, giving a final sample of 37 practices. The response rate $(36 \%)$ varied among models and regions (Table 1) and was lowest among small fee-for-service and walk-in clinics. The response rates for community health centres and family medicine groups and in region 3 were within our target range (50\%).

Of 3206 patients who reported being eligible, $2252(70.2 \%)$ agreed to participate. Upon chart review, we deemed 744 to be ineligible, and 51 patients could not be matched to the RAMQ database because there was an error in the RAMQ number recorded. The final sample comprised 1457 patients. Patient characteristics $(n=1457)$ for the eligible and included practices are shown in Table 2. Perceived economic status and exposure to interdisciplinary care are the patients' characteristics that showed the most variability between clinics.

Technical quality of care scores among the participating practices were skewed, ranging from 66.7 (standard deviation [SD] 7.3) to 70.1 (SD 10.5). On average, half of the patients $(51.1 \%)$ reached their target for LDL cholesterol, compared with $57.0 \%$ for $\mathrm{HbA} 1 \mathrm{c}$ and $61.8 \%$ for blood pressure.

Table 3 summarizes the results of the multilevel linear regression analyses for the 3 technical quality scores. The proportion of the variance attributable to the organizational level (model 1, empty model) varied according to the technical quality scores and was greater for the chronic and prevention technical score than for the 2 others. Physician remuneration method, extent of sharing of administrative resources (rent, staff, patients' charts, income), presence of allied health professionals and/or specialist physicians, presence of competence-maintenance mechanisms (continuous professional development activities and chart audits) and average organizational access to the practice were strongly associated with the overall technical quality score (model 2, organizational characteristics). The number of physicians and the average Team Climate Inventory score were modestly associated with the technical quality score. Moderate level of group practice (sharing of administrative resources) was negatively associated with overall technical quality. Physician remuneration method was not associated with technical quality score for chronic and preventive care, whereas the duration of visits and the number of diagnostic and therapeutic procedures available on-site were. Physician remuneration method was closely associated with visit duration in our bivariate analysis (Spearman $\rho=0.67, p<0.001$; data not shown).

In our logistic regression analyses, no organizational characteristics or patient-level variables were consistently associated with the treatment targets.

\section{Interpretation}

Our findings suggest high-quality care can be achieved by practices with different organizational models. We identified organizational factors that, beyond models, can improve care. As we had hypothesized, organizational contribution to technical quality differed according to the nature of care considered. Although the contribution of organizational factors to episodic care appears modest, their contribution to chronic illness care $(24 \%, 95 \%$ CI 22.6-25.3) is important. Few authors have reported on the magnitude of organizational contribution to quality of care. ${ }^{7,36-38}$

Our observations about practice size agree with previous reports. ${ }^{6,11,16}$ The observed associations with visit duration and physician remuneration should, however, be viewed with caution. Research suggests that salary-based remuneration is less efficient than blended remuneration ${ }^{6,39}$ or fee-for-service schemes. ${ }^{40}$ The ratio of nurses to family physicians is smaller in Quebec models than in most primary care models in Canada, ${ }^{6}$ and none of our practices used electronic medical records. A recent study suggests that, when these 2 features are present, the influence of visit duration and remuneration on quality of care scores disappears. ${ }^{9}$ Our results suggest that longer visits may have been needed for highquality care for chronic illnesses to compensate

Table 2: Distribution of characteristics of 1457 patients across the 37 practices

\begin{tabular}{|c|c|c|}
\hline \multirow{2}{*}{$\begin{array}{l}\text { Characteristic } \\
\text { Age of patients per practice, yr, mean }\end{array}$} & \multicolumn{2}{|c|}{$\begin{array}{l}\text { Mean or mean } \\
\text { proportion (SD) }\end{array}$} \\
\hline & 59.1 & (6.5) \\
\hline Female, \% & 56.5 & $(10.9)$ \\
\hline \multicolumn{3}{|l|}{ Perceived economic status, \% } \\
\hline Comfortable & 22.2 & $(10.1)$ \\
\hline Sufficient income & 56.6 & $(9.3)$ \\
\hline Poor or very poor & 21.2 & $(10.0)$ \\
\hline $\begin{array}{l}\text { No. of patients with at least } 1 \text { of the target } \\
\text { chronic illnesses per practice, mean }\end{array}$ & 25 & (11) \\
\hline $\begin{array}{l}\text { No. of patients with at least } 1 \text { of the target } \\
\text { episodic illnesses per practice, mean }\end{array}$ & 16 & (7) \\
\hline $\begin{array}{l}\text { Burden of comorbidity by ambulatory care group } \\
\text { classification (out of } 5 \text { ) }\end{array}$ & 3.14 & (0.35) \\
\hline 12-Item Short Form Survey, physical & 41.0 & (3.3) \\
\hline 12-Item Short Form Survey, mental & 48.7 & (3.8) \\
\hline $\begin{array}{l}\text { Interdisciplinary follow-up at the practice } \\
\text { (chronic-care patients only), } \%\end{array}$ & 36.6 & $(27.9)$ \\
\hline Follow-up by a specialist physician, $\%$ & 42.5 & $(11.3)$ \\
\hline No. of years at the practice, no. & 12.5 & $(5.2)$ \\
\hline Visits at the practice with the regular physician, \% & 81.8 & (16.7) \\
\hline
\end{tabular}


for the absence of electronic medical records and strong interdisciplinary support.

The relation observed between Team Climate Inventory, high intensity of group practice and the existence of mechanisms for maintaining professional skills shed more light than previous research on the mechanisms by which high-performing primary care practices develop and maintain strong

Table 3: Results of the multilevel linear regression analysis for the 3 technical quality of care scores considered

\begin{tabular}{|c|c|c|c|}
\hline \multirow[b]{2}{*}{ Model; variable* } & \multicolumn{3}{|c|}{ Technical quality score, estimate $(95 \% \mathrm{Cl})$} \\
\hline & Episodic illness & $\begin{array}{l}\text { Chronic illness plus } \\
\text { prevention }\end{array}$ & Overall \\
\hline \multicolumn{4}{|l|}{ Model 1 (empty model) } \\
\hline \multicolumn{4}{|l|}{ Fixed effects } \\
\hline Intercept & 70.0 (66.4 to 73.5$)$ & 67.2 (64.8 to 69.5$)$ & 68.5 (66.0 to 70.9 ) \\
\hline \multicolumn{4}{|l|}{ Random effects } \\
\hline Organizational-level variance component & 84.8 (76.0 to 93.6$)$ & 45.7 (41.6 to 49.8 ) & 50.5 (46.1 to 54.9 ) \\
\hline Patient-level variance component & 488.2 (478.7 to 497.7$)$ & $144.7(142.4$ to 147.0$)$ & 279.7 (276.3 to 283.1 ) \\
\hline $\begin{array}{l}\text { Proportion of the variance attributable to the } \\
\text { organizational level }\end{array}$ & $14.8 \%(13.7 \%$ to $15.8 \%)$ & $24.0 \%(22.6 \%$ to $25.3 \%)$ & $15.3 \%(14.3 \%$ to $16.2 \%)$ \\
\hline \multicolumn{4}{|l|}{ Model 2 (organizational characteristics) } \\
\hline \multicolumn{4}{|l|}{ Fixed effects } \\
\hline Intercept & 42.5 (31.8 to 53.2 ) & 50.9 (39.1 to 62.7$)$ & 26.5 (13.8 to 39.2$)$ \\
\hline $\begin{array}{l}\text { Physician remuneration method (mostly hourly } \\
\text { or salaried v. mostly fee-for-service) }\end{array}$ & $20.4(13.4$ to 27.4$)$ & & 27.0 (19.0 to 35.0 ) \\
\hline $\begin{array}{l}\text { No. of physicians (centred around the } \\
\text { mean of the } 37 \text { practices }=7 \text { ) }\end{array}$ & & 0.8 (0 to 1.6$)$ & 1.2 (0.6 to 1.8$)$ \\
\hline \multicolumn{4}{|l|}{ Presence of other professionals on-site (v. none) } \\
\hline $\begin{array}{l}\text { Physician specialists (with or without other } \\
\text { health care professionals) }\end{array}$ & & $9.4(-0.9$ to 19.7$)$ & 19.6 (8.3 to 30.9$)$ \\
\hline Other health care professionals & & $10.8(1.1$ to 20.5$)$ & 15.3 (5.4 to 25.2$)$ \\
\hline \multicolumn{4}{|l|}{$\begin{array}{l}\text { Duration of follow-up/emergency visits by } \\
\text { appointment (v. short duration }[\leq 10 \mathrm{~min}])\end{array}$} \\
\hline Long ( $\geq 30 \mathrm{~min}$ ) & & $18.6(8.1$ to 29.1$)$ & \\
\hline \multicolumn{4}{|l|}{ Average (15-20 min) } \\
\hline $\begin{array}{l}\text { Diagnostic/therapeutic procedures available } \\
\text { on-site (many v. few) }\end{array}$ & & 8.0 (1.6 to 14.4$)$ & \\
\hline \multicolumn{4}{|l|}{$\begin{array}{l}\text { Group practice (sharing of administrative } \\
\text { resources) (v. low) }\end{array}$} \\
\hline High & 8.6 (0.4 to 16.8$)$ & & 7.6 (0.8 to 14.4$)$ \\
\hline Moderate & & & $-8.6(-16.6$ to -0.6$)$ \\
\hline $\begin{array}{l}\text { Mechanisms for continuous professional } \\
\text { development and/or chart audits on site (v. no) }\end{array}$ & & & 7.7 (3.0 to 12.4$)$ \\
\hline Participation in a local accessibility network & 10.2 (4.0 to 16.4$)$ & & \\
\hline $\begin{array}{l}\text { Team Climate Inventory score (centred around } \\
\text { the mean of the } 37 \text { practices }=18 \text { ) }\end{array}$ & & & $1.3(0.1$ to 2.5$)$ \\
\hline $\begin{array}{l}\text { Average organizational access (centred } \\
\text { around the mean of the } 37 \text { practices }=5.2 \text { ) }\end{array}$ & & 5.7 (2.8 to 8.6$)$ & 4.9 (2.6 to 7.2$)$ \\
\hline \multicolumn{4}{|l|}{ Random effects } \\
\hline Organizational-level variance component & 8.9 (5.7 to 12.1$)$ & 17.8 (15.4 to 20.2$)$ & $11.3(9.5$ to 13.1$)$ \\
\hline Patient-level variance component & 477.3 (468.0 to 486.6 ) & $140.8(138.6$ to 143.0$)$ & 260.1 (256.7 to 263.5$)$ \\
\hline $\begin{array}{l}\text { Proportion of the empty-model (model } 1 \text { ) } \\
\text { organizational-level variance attributable to the } \\
\text { organizational variables entered (model } 2 \text { ) }\end{array}$ & $89.5 \%(87.1 \%$ to $92.5 \%)$ & $61.0 \%(59.4 \%$ to $63.0 \%)$ & $77.7 \%(76.1 \%$ to $79.4 \%)$ \\
\hline
\end{tabular}


connectedness, good communication, concern for quality and sustained competence and leadership. ${ }^{41-43}$ Our observation that moderate intensity of group practice (v. low-intensity group practice, where physicians behave more like solo practitioners under the same roof) is negatively associated with quality of care is interesting in light of some research suggesting that solo practitioners offer good quality of care. ${ }^{11}$ Research suggests that accessibility is associated with lower rates of emergency visits and admission to hospital, ${ }^{3}$ and we found a positive association between organizational accessibility, measured as the capacity to access the clinic for advice or an appointment, and technical quality of care. Organizational accessibility should be viewed as an inherent dimension of quality of care, much like the provision of evidence-based care.

Finally, our results suggest that the contribution of organizational characteristics to blood pressure, HbA1c and LDL cholesterol control is more complex than anticipated. Others have also reported a weak relation between technical quality scores and treatment targets as defined in clinical practice guidelines. ${ }^{44}$ Attaining these targets may depend on many factors, such as patients' capacity for self-care.

\section{Strengths and limitations}

We are confident in the internal validity of our results. We used reliable and validated measurements. The distributions of several of our indicators - control of blood pressure ${ }^{45}$ and $\mathrm{HbA1c},{ }^{46}$ organizational accessibility and continuity of care $^{11}$ - are comparable to what has been reported in other studies. Using a composite score encompassing care for episodic and chronic illnesses as well as prevention as the primary outcome measure was an important design consideration. ${ }^{47}$ This decision was not based on a desire to increase the power of the study; it was based on our definition of high-quality primary care and on our primary objective.

The response rate fell short of our target of $50 \%$ but was similar to rates in comparable studies. ${ }^{48,49}$ We reached our targeted response rate for community health centres and family medicine groups. Clearly, our results do not apply to small traditional fee-for-service practices and walk-in clinics; however, those types of practices are not considered models of the future. ${ }^{4,5}$ This self-selection bias would be problematic if our objective had been to draw inferences from our observations to existing organizational models; however, we focused on identifying organizational characteristics associated with quality of care. We believe that this selection bias is more likely to result in an underestimation of the contribution of organizational char- acteristics to quality of care by resulting in less variability between practices.

\section{Conclusion}

We identified a common set of organizational characteristics associated with high-quality primary care (e.g., effectiveness of team process, presence of competence-maintenance mechanisms, organizational access). Most of these characteristics are amenable to change, through either health policy or practice-level organizational changes. Beyond investing in new delivery models, decision-makers should invest in helping primary care practices reach a high level of functioning by fostering group practice and effective team-based care.

\section{References}

1. Starfield B, Powe NR, Weiner JR, et al. Costs vs. quality in different types of primary care settings. JAMA 1994;272:1903-8.

2. Starfield B. Primary care, balancing health needs, services, and technology. New York (NY): Oxford University Press; 1998: 8-9.

3. McMurchy D. What are the critical attributes and benefits of a high-quality primary healthcare system? Ottawa $(\mathrm{ON})$ : Canadian Health Services Research Foundation; 2009.

4. Lamarche P, Beaulieu MD, Pineault R, et al. Choices for change: the path for restructuring primary healthcare services in Canada. Ottawa (ON): Canadian Health Services Research Foundation; 2003.

5. Hutchison B, Levesque JF, Strumpf E, et al. Primary health care in Canada: systems in motion. Milbank Q 2011;89:256-88.

6. Russell GM, Dahrouge S, Hogg W, et al. Managing chronic disease in Ontario primary care: the impact of organizational factors. Ann Fam Med 2009;7:309-18.

7. Glazier RH, Klein-Geltink J, Kopp A, et al. Capitation and enhanced fee-for-service models for primary care reform: a population-based evaluation. CMAJ 2009;180:E72-81.

8. Dahrouge S, Hogg WE, Russell G, et al. Impact of remuneration and organizational factors on completing preventive manoeuvres in primary care practices. CMAJ 2012;184:E135-43.

9. Hutchison B, Ostbye T, Barnsley J, et al. Patient satisfaction and quality of care in walk-in clinics, family practices and emergency departments: the Ontario Walk-In Clinic Study. CMAJ 2003; 168:977-83

10. Shortell SM, Schmittdiel J, Wang MC, et al. An empirical assessment of high-performing medical groups: results from a national study. Med Care Res Rev 2005;62:407-34.

11. Haggerty JL, Pineault R, Beaulieu MD, et al. Practice features associated with patient-reported accessibility, continuity, and coordination of primary health care. Ann Fam Med 2008;6:116-23.

12. Ministère de la santé et des services sociaux. Groupes de médecine de famille: Document synthèse. Québec (QC): Ministère de la santé et des services sociaux; 2002.

13. Levesque JF, Pineault R, Provost S, et al. Assessing the evolution of primary healthcare organizations and their performance (2005-2010) in two regions of Quebec province: Montréal and Monteregie. BMC Fam Pract 2010;11:95.

14. Anderson NR, West MA. Measuring climate for work group innovation: development and validation of the team climate inventory. J Organ Behav 1998;19:235-58.

15. Lemieux-Charles L, McGuire WL. What do we know about health care team effectiveness? A review of the literature. Med Care Res Rev 2006;63:263-300.

16. Campbell SM, Hann M, Hacker J, et al. Identifying predictors of high quality care in English general practice: observational study. BMJ 2001;323:784-7.

17. Goh TT, Eccles MP. Team climate and quality of care in primary health care: a review of studies using the Team Climate Inventory in the United Kingdom. BMC Res Notes 2009;2:222.

18. Agrell A, Gustafson R. The Team Climate Inventory (TCI) and group innovation: a psychometric test on a Swedish sample of work groups. J Occup Organ Psychol 1994;67:143-51.

19. Ragazzoni P, Baiardi P, Zotti AM, et al. Research note: Italian validation of the team climate inventory: a measure of team climate for innovation. J Manag Psychol 2002;17:325-36. 
20. Mathisen GE, Einarsen S, Jorstad K, et al. Climate for work group creativity and innovation: Norwegian validation of the team climate inventory (TCI). Scand J Psychol 2004;45:383-92.

21. Strating MM, Nieboer AP. Psychometric test of the Team Climate Inventory-short version investigated in Dutch quality improvement teams. BMC Health Serv Res 2009;9:126.

22. Boada-Grau J, de Diego-Vallejo R, de Llanos-Serra E, et al. [Short Spanish version of Team Climate Inventory (TCI-14): development and psychometric properties]. Psicothema 2011;23:308-13.

23. Gandek B, Ware JE, Aaronson NK, et al. Cross-validation of item selection and scoring form the SF-12 Health Survey in nine countries: results from the IQOLA Project. International Quality of Life Assessment. J Clin Epidemiol 1998;51:1171-8.

24. Rosen AK, Reid R, Broemeling AM, et al. Applying a riskadjustment framework to primary care: Can we improve on existing measures? Ann Fam Med 2003;1:44-51.

25. Safran DG, Kosinski M, Tarlov AR, et al. The Primary Care Assessment Survey: tests of data quality and measurement performance. Med Care 1998;36:728-39.

26. Shi L, Starfield B, Xu J. Validating the Adult Primary Care Assessment Tool. J Fam Pract 2001;50:161-75.

27. Haggerty JL, Levesque JF, Santor DA, et al. Accessibility from the patient perspective: comparison of primary healthcare evaluation instruments. Healthc Policy 2011;7:94-107.

28. Burge F, Haggerty JL, Pineault R, et al. Relational continuity from the patient perspective: comparison of primary healthcare evaluation instruments. Healthc Policy 2011;7:124-38.

29. Beaulieu MD, Haggerty JL, Beaulieu C, et al. Interpersonal communication from the patient perspective: comparison of primary healthcare evaluation instruments. Healthc Policy 2011;7:108-23.

30. Campbell SM, Hann M, Hacker J, et al. Quality assessment for three common conditions in primary care: validity and reliability of review criteria developed by expert panels for angina, asthma and type 2 diabetes. Qual Saf Health Care 2002;11:125-30.

31. Kirk SA, Campbell SM, Kennell-Webb S, et al. Assessing the quality of care of multiple conditions in general practice: practical and methodological problems. Qual Saf Health Care 2003;12:421-7.

32. Barnsley J, Berta W, Cockerill R, et al. Identifying performance indicators for family practice: assessing levels of consensus. Can Fam Physician 2005;51:700-1.

33. Beaulieu MD, Rivard M, Hudon E, et al. Comparative trial of a short workshop designed to enhance appropriate use of screening tests by family physicians. CMAJ 2002;167:1241-6.

34. Walker S, Mason AR, Claxton K, et al. Value for money and the Quality and Outcomes Framework in primary care in the UK NHS. Br J Gen Pract 2010;60:e213-20.

35. Hox JJ. Multilevel analysis: techniques and applications. Mahwah (NJ): Lawrence Erlbaum Associates; 2002.

36. Marceau L, McKinlay J, Shackelton R, et al. The relative contribution of patient, provider and organizational influences to the appropriate diagnosis and management of diabetes mellitus. $J$ Eval Clin Pract 2011;17:1122-8.

37. Rodriguez HP, Scoggins JF, von Glahn T, et al. Attributing sources of variation in patients' experiences of ambulatory care. Med Care 2009;47:835-41.

38. Lemieux V, Lévesque J-F, Ehrmann-Feldman D. Are primary healthcare organizational attributes associated with patient selfefficacy for managing chronic disease? Healthc Policy 2011;6: e89-105.

39. Gosden T, Forland F, Kristiansen IS, et al. Capitation, salary, fee-for-service and mixed systems of payment: effects on the behaviour of primary care physicians. Cochrane Database Syst Rev 2000;(3):CD002215.

40. Milliken O, Devlin RA, Barham V, et al. Comparative efficiency assessment of primary care service delivery models using data envelopment analysis. Can Public Policy 2011;37:85-109.

41. Orzano AJ, Tallia AF, Nutting PA, et al. Are attributes of organizational performance in large health care organizations relevant in primary care practices? Health Care Manage Rev 2006;31:2-10.

42. Feifer C, Nemeth L, Nietert PJ, et al. Different paths to highquality care: three archetypes of top-performing practice sites. Ann Fam Med 2007;5:233-41.

43. Solberg LI, Hroscikoski MC, Sperl-Hillen JM, et al. Transform- ing medical care: case study of an exemplary, small medical group. Ann Fam Med 2006;4:109-16.

44. de Belvis AG, Pelone F, Biasco A, et al. Can primary care professionals' adherence to Evidence Based Medicine tools improve quality of care in type 2 diabetes mellitus? A systematic review. Diabetes Res Clin Pract 2009;85:119-31.

45. Leenen FH, Dumais J, McInnis NH, et al. Results of the Ontario survey on the prevalence and control of hypertension. CMAJ 2008:178:1441-9.

46. Harris SB, Ekoe JM, Zdanowicz Y, et al. Glycemic control and morbidity in the Canadian primary care setting (results of the diabetes in Canada evaluation study). Diabetes Res Clin Pract 2005; 70:90-7.

47. Freemantle N, Calvert M, Wood J, et al. Composite outcomes in randomized trials: Greater precision but with greater uncertainty? JAMA 2003;289:2554-9.

48. Dahrouge S, Hogg W, Russell G, et al. The Comparison of Models of Primary Care in Ontario (COMP-PC) study: methodology of a multifaceted cross-sectional practice-based study. Open Med 2009;3:e149-64.

49. Liddy C, Singh J, Hogg W, et al. Comparison of primary care models in the prevention of cardiovascular disease - a cross sectional study. BMC Fam Pract 2011;12:114.

Affiliations: Centre de recherche du CHUM (CR-CHUM) (Beaulieu, Del Grande), Université de Montréal, Montréal, Que.; Département de médecine familiale et de médecine d'urgence (Beaulieu, Duplain, Hudon), Université de Montréal, Montréal, Que.; Department of Family Medicine (Haggerty), McGill University, Montréal, Que.; Department of Epidemiology and Biostatistics (Tousignant), McGill University, Montréal, Que.; The Institute of Health Policy, Management and Evaluation (Barnsley), University of Toronto, Toronto, Ont.; Department of Family Medicine (Hogg), University of Ottawa, Ottawa, Ont.; Département des sciences de la santé communautaire (Geneau), Université de Sherbrooke, Sherbrooke, Que.; École nationale d'administration publique (Denis), Montréal, Que.; Agence de la santé et des services sociaux de la Mauricie-Centre du Québec (Bonin), Trois-Rivières, Que.; Département de sexologie (Dragieva), Université du Québec à Montréal, Montréal, Que.

Contributors: Marie-Dominique Beaulieu, Jeannie Haggerty, Pierre Tousignant, Janet Barnsley, William Hogg, Robert Geneau, Éveline Hudon, Réjean Duplain, Jean-Louis Denis, Lucie Bonin and Claudio Del Grande contributed to the study conception and design and to the analysis and interpretation of the data. Natalyia Dragieva was the statistician in charge and contributed to the data analysis and interpretation of the data. Claudio Del Grande was the project's research coordinator; he contributed to data acquisition and to the drafting of the manuscript. All of the authors revised the article for important intellectual content and approved the final version submitted for publication.

Funding: This study was funded by the Canadian Institutes of Health Research (CIHR; grant no. MOP-844). CIHR reviewed and approved the research protocol and had no involvement in the conduct of the study or in the writing of the manuscript.

Acknowledgements: The authors thank Johanne Goudreau for her involvement in the project's planning and protocol development; Professor Michal Abrahamowicz for his advice on calculating sample size and on the overall analytical strategy; Professor Michael A. West, who gave permission to use the Team Climate Inventory in this study; and Donna Riley for helping with the translation and preparation of the article. 